\title{
Understanding The Purpose and Potential Popularity of Mobile Phone Use in Zambia's Maize Production
}

\author{
Gershom Endelani Mwalupaso ${ }^{1,2}, \mathrm{Xu} \operatorname{Tian}^{1}$, Eunice Matafwali ${ }^{2}$, Moses Chansa Mwamba ${ }^{3}$, \\ Essiagnon John-Philippe Alavo ${ }^{1}$, Aseres Mamo Ethetie ${ }^{1}$, Mariko Korotoumou ${ }^{1} \&$ Fariya Waseem $^{1}$ \\ ${ }^{1}$ College of Economics and Management, China Center for Food Security Studies, Nanjing Agricultural \\ University, Nanjing, China \\ ${ }^{2}$ Department of Agribusiness and Agriculture, Prince G Academy and Consultancy, Kabwe, Zambia \\ ${ }^{3}$ College of Resource and Environment, Southwest University, Chongqing, China \\ Correspondence: Tian Xu, College of Economics and Management, China Center for Food Security Studies, \\ Nanjing Agricultural University, No. 1 Weigang, Nanjing, China. Tel: 86-187-2401-0668. E-mail: \\ xutian@njau.edu.cn
}

$\begin{array}{ll}\text { Received: January 31, } 2019 & \text { Accepted: March 7, } 2019 \quad \text { Online Published: May 15, } 2019 \\ \text { doi:10.5539/jas.v11n6p32 } & \text { URL: https://doi.org/10.5539/jas.v11n6p32 }\end{array}$

The research is financed by Priority Academic Program Development of Jiangsu Higher Education Institutions (PAPD) and Prince G Academy and Consultancy (PGAC).

\begin{abstract}
There is a growing use of mobile phones in rural areas on account of its relative inexpensiveness and lack of requirement for an urban environment. As a platform for accessing information through text messages and voice calls, farmers are able to collect agricultural information which may lead to higher productivity due to technology spillover. If the use of mobile phones contributes to the improvement of farmers' productivity, their agricultural output level should increase. In this study, we investigate the adoption of mobile phones to obtain agricultural information and its effect on smallholder maize farmers' production using cross-sectional data from Zambia. Understanding such causal effects is indispensable especially against the background of vision 2030. The propensity score matching (PSM) method was adopted to estimate the average treatment effect of treated of mobile phone adoption in agriculture. We found that the use of mobile phones significantly increases farmers' productivity, by about $30 \%$. If farmers start to adopt mobile phones to collect agricultural information, the total maize output would also increase by $30.36 \%$, which would culminate in feeding two more people per household daily for the whole year. Therefore, we cautiously conclude that mobile phone use in agriculture serves the purpose of contributing to the fight against hunger via enhancing maize production and this is driving its popularity among smallholder farmers in rural Zambia.
\end{abstract}

Keywords: mobile phone use, productivity, maize production, propensity score matching, Zambia

\section{Introduction}

For the past decade and at present, the use of information communication technology (ICT) has been remarkable in hastening the development process the world over. In agriculture, for instance, the attainment of higher agricultural production and adoption of innovations is facilitated by the use of ICT (Admassie \& Ayele, 2004). As is the case with other sectors, information is a critical input in agriculture enabling farmers to evaluate prospects that could improve their agricultural productivity promptly (Verheye, 2000). However, it is worth noting that information searching costs are often very high in agriculture. Policymakers and economists attribute this to limited telecommunications infrastructure and transport. They instead promote agricultural extension systems as a means of addressing information asymmetries among agricultural households (Dreze, Sen, \& Hussain, 1995; Sen, 1976, 1981) but evidence of the impact is mixed even after decades of investment in the program. Aker (2010) concludes that the untimeliness or irrelevancy of the information provided is also possibly the cause. This has consequently encouraged the agricultural industry to embrace ICTs. These comprise but are not limited to television, the Internet, radio, mobile phones, and personal computers. In organizing farmers and creating awareness, the mobile phone is the most effective tool for expediting the adoption and application of innovations and technologies in agriculture. 
Therefore, the extent and nature of ICT usage in developing countries is key to the success of development programs in agriculture (Ango, Illo, Abdullahi, Maikasuwaand, \& Amina, 2013).In support, Ali and Kumar (2011) assert that users of ICTs show significantly better decision-making aptitude as compared to non-users in various agricultural practices across the agricultural supply chain.

The flow of information in farming communities is speedy after the introduction of mobile phones, which has enabled easier communication. Information is a prerequisite for farmers if they are to undertake their agricultural tasks effectively and improve their agricultural practices (Aina, 1985; Babu, Glendenning, Asenso-Okyere, \& Govindarajan, 2012). As the adage goes "information is power." It lessens the load of the task and activity for farmers and builds their confidence. The explanation is that access to information eventually leads to higher efficiency due to technology spillover (Aker \& Ksoll, 2016; Kirk et al., 2011). Thus, the use of mobile phone meets these requirements with undeniable benefits accruing to the farmers, one of which is food security through higher productivity (Wiebe, 2003). The useful information farmers obtain via mobile phones frees them from making decisions blindly, allowing them to know which crops are profitable and will enable the country to be food secure (Aker, 2008). However, the use of mobile phones is subject to various assumptions. The primary ones are that only when search costs are the main reason for inefficiency will farmers benefit, and that information is available and easily accessed (Shimamoto, Yamada, \& Gummert, 2015). Fortunately, the potential to improve farmers' welfare and new opportunities to overcome transaction and search costs have been achieved through persistent progress in mobile phone coverage. To expedite the use in rural agricultural communities, Jain, Kumar, and Singla (2015) caution on the need for localization and to integrate the native language of farmers in mobile technologies.

Agriculture is relied on by the majority of Africa's indigent population. For those living in rural areas, the situation is characterized by poor market information, poor infrastructure, low literacy levels, bad roads, high levels of poverty, and subsistence farming. Due to poverty, some essential inputs necessary for productivity are unaffordable and, thus, not used (Chukwuji, Inoni, \& Oyaide, 2006). It is for this reason that most sub-Saharan Africa (SSA) countries have come up with ways of supporting poor farmers, with the aim of eradicating hunger. Hunger remains prevalent, driven by gender inequality in the distribution of food, inability to purchase food, and inadequate means or infrastructure to distribute food (Benin, Pratt, Wood, \& Guo, 2011; Brown, 2001). The situation is likely to be worsened as FAO adds that 234 million people (26.8 percent of the SSA population) were undernourished/ hungry in 2011 and 2012. Compared to 1992 where 170 million people were hungry, there was an increase of about 38 percent hungry people in 2012 (FAO, WFP, \& IFAD, 2012; Wheeler \& Von Braun, 2013). To curb it, increased agricultural output via innovation (disease-resistant and high-yield seeds) and new technologies are among the strategies employed (Samuel, 2007). To the disappointment of many, these strategies have not made much difference, and the productivity of farmers has been called into question.

Thirtle, Lin, and Piesse (2003) posit that agricultural growth through productivity is the desired core component of any development scheme. Modern agriculture that makes use of various facilities in enhancing agricultural production is expected. This will culminate in structurally renovated economies evident in employment opportunities, food security, and hunger reduction. Considering the growing population and land use competition (Lynd \& Woods, 2011) in Zambia, improving the productivity of farmers to the extent that it increases output is a prerequisite. The question many policymakers are asking is how productivity will be realized. Most researchers point out that the majority of farmers are information-starved (Aker \& Mbiti, 2010) and advocacy is implemented to ensure that the agricultural sector has a smooth flow of information, facilitating improvement in farmers' knowledge on most issues regarding their farming tasks and prudent decision-making.

Consequently, mobile phones are increasingly being used to tackle challenges related to the distribution of food supplies, employment, and production by improving the living standard through productivity (Asongu \& Kodila-Tedika, 2017). The mobile phone may be a much-needed solution to narrow the gap between real and potential outputs by means of increasing farmers' productivity through access to information. In Zambia agricultural productivity analysis has shown that if the output is to grow at a rate that meets the rising food demand, progress in the efficiency of maize production is essential for farmers (Hayami \& Ruttan, 1970; Muzari, Gatsi, \& Muvhunzi, 2012). Many agricultural policy discussions in Zambia revolve around the attainment of higher maize production. Despite the emphasis on the deployment of mobile technologies in agriculture, the utilization of the technology to improve smallholders' maize production remains poorly understood in Zambia. Maize production is a crucial policy issue because the southern African country has experienced intermittent food deficit in the past few years in spite of its considerable agricultural potential. Maize is the staple crop in Zambia, and its production levels have a direct impact on hunger eradication. Therefore, this study focuses on the impact of mobile phone use on maize productivity in Zambia. 
According to Ferguson (1966), production is merely a process of achieving output (finished products) after transforming an input (resources), and the primary aim of any production system, given a specific amount of input, is the optimal realization of large output (S. Rahman \& M. Rahman, 2009). This is referred to as productivity. To analyze productivity, several techniques exists (Färe, Grosskopf, \& Lovell, 1984; Farrell, 1957) and one of them adopted in this study is technical efficiency (TE) scores, which Koopmans (1951) defines with clarity, stating that a producer is technically efficient if it is no longer possible to produce any further output without producing less of some other output or using more of some input. To do so, farmers need information that enables them to be more knowledgeable about the various agricultural practices available, sources of quality inputs, make informed decisions quickly, and efficiently allocate resources because technical efficiency demonstrates the ability of farmers to transform available inputs into maximum attainable output given available technology (Bravo-Ureta et al., 2007). The study meticulously addresses the question; can mobile phones improve the technical efficiency of smallholder maize farmers in Zambia?

The study contributes to the literature in two ways. First, we attempt to relate mobile phone use to a measure of productivity, technical efficiency scores. Comprehension of such effects is essential particularly against the background of vision 2030 which aspires to reduce hunger and malnutrition. Regardless of the continuous challenge posed by diseases and pests, soil fertility depletion, recurring droughts, and the use of unimproved seeds sustained development in agriculture is expected to eradicate hunger. Second, we use PSM, an econometric method, which is fundamentally advantageous in the realization of unbiased estimates. By comparing farmers with similar characteristics through the aid of PSM and coming up with the causal effect of mobile phone use, appropriate and effective policy formulation is guaranteed.

The rest of the paper is structured as follows: Section 2 gives details of the data and the empirical strategy; Section 3 presents the results and discussion and; Section 4 provides conclusions and policy implications.

\section{Material and Methods}

\subsection{Data}

The study makes use of data collected from a farm household field survey conducted in 2018 in central Zambia (Mkushi district) as part of a project on promoting mobile phone use in agriculture. The district is divided into 22 farming camps and has a population of 148,814 people (CSO, 2017). The smallholder farmers in the area grow maize as the primary crop in addition to beans, cassava, millet, and various vegetables. The target participants of this study are mobile phone users and non-users maize growers.

The analysis in this study is based on 201 farmers from three farming camps (Nshinso, Lweo, and Fiwela) who were randomly sampled using the list from the Ministry of agriculture in the areas. The choice of the camps was influenced by the availability of mobile phone network coverage. We collected extensive information on the ownership of mobile phones, whether the use of mobile phones was done to obtain agricultural information and demographic characteristics. A structured pre-tested questionnaire was administered by well trained and experienced enumerators to ensure that measurement errors are minimized in the estimation results. The survey permitted us to evaluate the impact of improved access to agricultural information through the use of mobile phones on the technical efficiency while controlling for differences in household characteristics that could affect the quality of the estimation.

\subsection{Measurement of Key Variables}

Mobile phone use is the main explanatory variable in this study. We consider a household as a mobile phone user if at least one adult members in the household own and use the device to collect agricultural information. The variable is captured as a dummy where 1 denotes user and 0 otherwise.

The outcome variable of interest is technical efficiency scores, a measure of productivity, which is extracted from the stochastic frontier analysis of the sampled households. The estimation results of the technical efficiency are presented in Appendix A (Table A1)

\subsection{Empirical Strategy}

Three procedures were undertaken to achieve the study's goal of investigating the causal effects of mobile phone adoption in maize production. First, we matched the observations between the groups using propensity score matching (PSM), a procedure which makes a comparison of different outcomes among participants in a manner that aids the estimation of the impact of the intervention. Second, we calculate the average treatment effect of the treated (ATT) in terms of efficiency scores using different matching algorithms. Finally, we made projections of the potential output in the case that non-users adopted mobile phones to collect agricultural information. 


\subsubsection{Propensity Score Matching}

The problem of causal inference in predicting treatment effects in observational studies is widely recognized by numerous researchers. The acknowledgment is that the estimate of the causal effect achieved via a comparison between the treatment group and the control group could be biased due to problems emanating from self-selection. Construction of the counterfactual result - that is, had treatment been absent, what would have occurred to participants - remains a significant challenge of a credible impact assessment (Heinrich, Maffioli, \& Vazquez, 2010). The fact is that the counterfactual outcome is not observed but instead requires econometric and statistical procedures to be estimated. In order to solve the problem of bias emanate from self-selection or some precise preferential program placement, PSM method, as established by Rosenbaum and Rubin (1983), is adopted in this study to estimate the efficiency gap between farmers who use mobile phones and those that do not. The motivation for this decision is that, given a high dimensionality of observable variables, PSM is particularly beneficial in overcoming the difficulties of determining the weighting scheme by providing natural schemes that simplify the achievement of unbiased estimates. There are two assumptions of PSM and, where these hold, the average treatment effect on the treated (ATT) can be estimated (Abadie \& Imbens, 2006).

The first assumption is that, given a set of observable covariates, the potential outcome is independent of the treatment allocated. This is called the conditional independence assumption (CIA) and is expressed as

$$
\left(\mathrm{Y}_{1}\right),\left(\mathrm{Y}_{0}\right) \perp \mathrm{T} \mid \mathrm{X}
$$

The second assumption is that perfect predictability is prevented by overlap or common support; this is expressed as,

$$
0<\mathrm{P}(\mathrm{T}=1 \mid \mathrm{X})<1
$$

The efficiency estimated from SFA is the outcome variable in the PSM model for the comparison between the users and non-users of mobile phones and simultaneously calculates the ATT whose empirical form is given in Equation (4). To estimate the impact of mobile phones on efficiency, the model is expressed as follows:

$$
\begin{gathered}
\mathrm{Y}_{\mathrm{i}}=\delta \mathrm{T}_{\mathrm{i}}+\mathrm{X}_{\mathrm{i}} \beta+\mathrm{z} \\
\mathrm{ATT}=\mathrm{E}[\mathrm{E}(\mathrm{Y} \mid \mathrm{T}=1, \mathrm{X}=\mathrm{x})]-[\mathrm{E}(\mathrm{Y} \mid \mathrm{T}=0, \mathrm{X}=\mathrm{x}) \mid \mathrm{T}=1]
\end{gathered}
$$

where, $Y_{i}$ is the technical efficiency of $i$ farmer, $X_{i}$ is a vector of impact variables for $i$ farmers, and $T_{i}$ is the treatment variable (use of mobile phone as a dummy) for i farmers. The coefficient $\delta$ measures the impact of mobile phone use on the outcome variables and $\mathrm{z}$ is the error.

\subsubsection{Matching Algorithms}

For robustness of estimates, three matching algorithms widely used by researchers are employed: nearest-neighbor matching (NNM), kernel matching (KM), and radius (caliper) matching (RM). As one of the most straightforward matching technique, variants of NNM include "without replacement" and "with replacement" where in the latter scenario, an untreated observation can be used more than once whereas the in the former case it can only be used once. In this matching procedure observation from the control group are selected as a match for treated observation regarding the closest propensity score. As for RM, it makes use of as many observations of the control group as are available within the caliper (maximum propensity score distance restricting matching range) to ensure the risk of poor matches is avoided. Finally, KM procedure has an advantage of achieving low variance because more observations are used in the process of comparing the outcome of the treated observations to a weighted outcome mean (where the highest weight is placed on untreated observation with scores closest to treated observations) of all the control observations.

\subsubsection{Projection of Potential Maize Output}

Mobile phone use (treatment) is the basis of comparison after matching because all the characteristics between the two groups are the same except for the treatment. Therefore, the percentage gain in efficiency scores of the users over the non-users translates to the attained percentage increase in maize production on account of better efficiency. Thus, projection in output is made based on the differences in the pooled mean efficiency score of each group. It is worth noting that in our projections we assume the users to have the same efficiency score while that of non-users changes to efficiency of users because by adopting the use of mobile phones in agriculture they will most likely attain the same level of efficiency score which their counterparts achieved. 


\section{Empirical Results and Discussion}

We approach this section using two policy-related questions to facilitate a discussion with direct policy implications. We begin by presenting the quality of the methods used to ensure that results are robust, unbiased and consistent.

\subsection{Quality of the PSM}

Given that mobile telephone use is endogenous as already established, a mere comparison of the technical efficiency between the two groups has no causal meaning as this may be a result of the dissimilarities in observed characteristics. Therefore, PSM was performed, and the validation of the quality is crucial before the presentation of results. According to Caliendo and Kopeinig (2008), a good match is achieved when much of the original observations are not eliminated from the final and covariate means for the control and treated groups are equal. Also, Rosenbaum and Rubin (1983) recommend checking t-test for significant differences and standardized bias because if the covariates used in the match are randomly distributed, the p-value (significance level) and the associated pseudo $\left(\mathrm{Ps}^{2}\right)$ should be insignificant and fairly low, respectively. Table 1 presents the covariates balance test after matching. The $\mathrm{p}$-values indicate that there is no significant difference in characteristics between the users and non-users as this is rejected at $10 \%$ significance level. The pseudo and bias reduction (Mean Bias and Med Bias) are also fairly low in value. Therefore, the insignificant $\mathrm{p}$-values, low standardized bias and $p s e u d o R^{2}$ after matching suggest that our PSM is acceptably effective regarding balancing the distribution of the selected covariates in the treated and control groups.

Table 1. Covariate balance test result

\begin{tabular}{|c|c|c|c|c|c|c|}
\hline \multirow{2}{*}{$\begin{array}{l}\text { Variables used in the } \\
\text { matching process }\end{array}$} & \multicolumn{3}{|c|}{ Mean } & \multicolumn{2}{|c|}{ t-test } & \multirow{2}{*}{$\mathrm{V}(\mathrm{T}) / \mathrm{V}(\mathrm{C})$} \\
\hline & Treated & Control & $\%$ bias & $\mathrm{T}$ & $\mathrm{p}>\mathrm{t}$ & \\
\hline Education & 7.786 & 8.071 & -10.700 & -0.670 & 0.507 & 0.880 \\
\hline Mobile phone ownership & 0.964 & 0.929 & 9.700 & 0.580 & 0.561 & \\
\hline Gender & 0.893 & 0.893 & 0.000 & 0.000 & 1.000 & \\
\hline Distance to cooperative & 4.929 & 4.786 & 4.600 & 0.240 & 0.810 & 1.270 \\
\hline Farming Experience & 17.321 & 16.143 & 10.400 & 0.450 & 0.651 & 1.320 \\
\hline Age & 2.500 & 2.536 & -4.100 & -0.140 & 0.888 & 1.090 \\
\hline Family size & 5.714 & 5.571 & 4.400 & 0.230 & 0.816 & 1.980 \\
\hline Maize sales (annual) & 4932.700 & 4915.700 & 0.400 & 0.020 & 0.982 & 1.290 \\
\hline $\mathrm{Ps} \mathrm{R}^{2}$ & LR chi2 & $\mathrm{p}>\mathrm{chi} 2$ & Mean Bias & Med Bias & $\mathrm{B}$ & $\mathrm{R}$ \\
\hline 0.018 & 1.42 & 0.994 & 5.5 & 4.5 & $30.9^{*}$ & 1.16 \\
\hline
\end{tabular}

Note. T represents the $\mathrm{t}$ statistic value while * if $\mathrm{B}>25 \%$, R outside $[0.5 ; 2]$.

Source: Authors' estimation.

After statistical validation of the quality of the matching, we also present a visual display of the scenario before and after matching to make the understanding of the quality of the matching easier. As shown by the box plot and density distribution in Figure 1a, the characteristics before matching were different between the treated and untreated. After matching, the figure vividly shows the balancing of the covariates across the two groups, and this is also verified by Figure 1b, which displays that the achieved substantial overlap between the two groups or a region of common support (the basis of comparison) after matching. 
psmatch2: Propensity Score

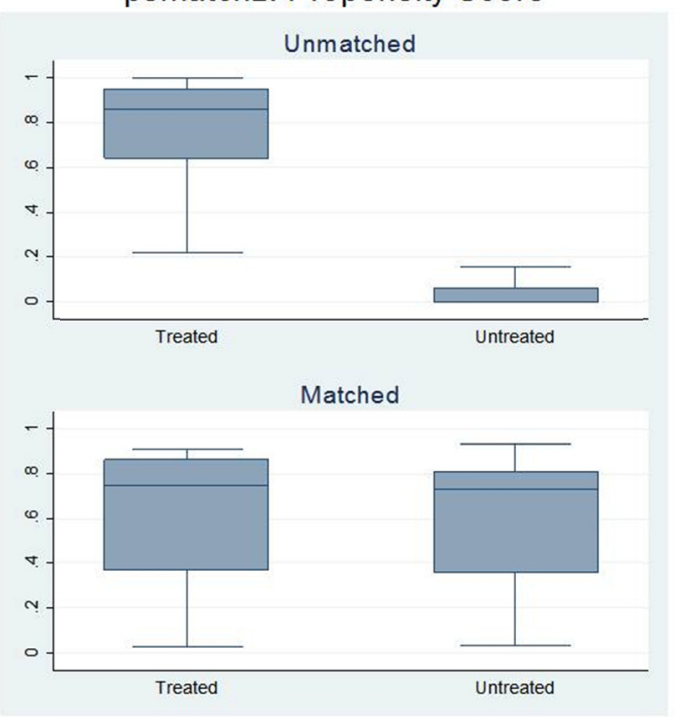

psmatch2: Propensity Score


Figure 1(a). Probability distribution and box plot before and after matching

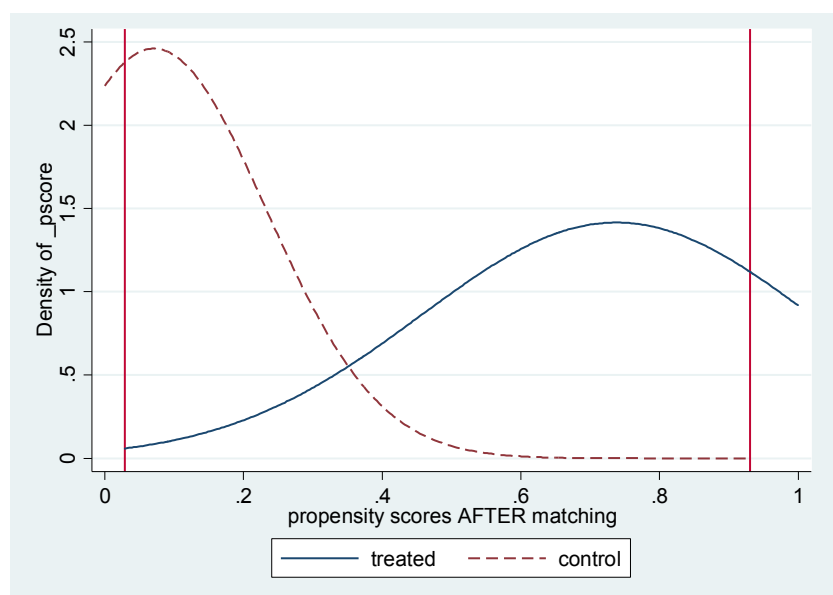

Figure 1(b). The region of common support after matching

Source: Authors' estimation.

\subsection{Is There a Difference in Technical Efficiency Between Users and Non-Users of Mobile Phones?}

An inspection of both groups before matching discloses that the difference in the technical efficiency means of the two groups is so high that, without a thorough evaluation procedure, an attempt to surmise that mobile phone use influences technical efficiency would not be dismissed (Table 2). Informed by the empirical strategy, the ATT is estimated by NNM without replacement, KM with normal bandwidth and RM with a caliper of 2. Using this meticulous econometric analytical procedure, all the matching algorithms employed, though they are slightly different, indicate that mobile phone use positively, robustly, and significantly affects technical efficiency as the average treated effect on the treated is about 30 percent of the non-users' mean at $1 \%$ significance level. These estimates are higher than in the work of Kelemu (2016), who found a 16 percent increase in technical efficiency. The underlining explanation is the variable used, mobile phone actual use and not mere ownership, as the latter tends to underestimate the impact. The mean variation in efficiency between groups may be accredited more to the mere participation of households in the treatment (mobile phone use) than to household characteristics. A low level of technical efficiency in any agricultural setting discloses the level of waste of the factors of production and ultimately output loss. Higher technical efficiency of farmers, on the other hand, implies that outputs are higher relative to the maximum obtainable output, given the inputs available and, as such, their contribution to food security and reduction of hunger and poverty is satisfactory. 
Table 2. ATT of mobile phone use on technical efficiency

\begin{tabular}{|c|c|c|c|c|c|}
\hline \multirow[t]{2}{*}{ Outcome Variable } & \multirow[t]{2}{*}{ Matching Algorithm } & \multicolumn{2}{|c|}{$\begin{array}{l}\text { Mean of Productivity Based } \\
\text { on Matched Observations }\end{array}$} & \multirow[t]{2}{*}{ ATT (Std.Err.) } & \multirow{2}{*}{$\begin{array}{l}\% \text { Change in } \\
\text { Productivity (+/-) }\end{array}$} \\
\hline & & $\overline{\text { Users }}$ & Non-Users & & \\
\hline Productivity scores before matching & & 0.794 & 0.630 & $0.164(0.011)$ & 26.03 \\
\hline \multirow{3}{*}{ Productivity scores after matching } & NNM (2) & 0.811 & 0.622 & $0.189(0.0258) * * *$ & 30.36 \\
\hline & Kernel (normal) & 0.811 & 0.616 & $0.195(0.0270) * * *$ & 31.67 \\
\hline & Radius (2) & 0.811 & 0.630 & $0.182(0.0173) * * *$ & 28.86 \\
\hline
\end{tabular}

Note. Figures in parentheses are standard errors of the mean, while *** indicates statistical significance levels at $1 \%$.

Source: Authors' estimation.

After establishing that mobile phone use significantly affects farmers' productivity, it is essential to delve into factors that may influence mobile phone use. Table 3 below presents the Probit function which reveals that education of the household head, ownership of the device and family size significantly impact the use of the mobile phone in agriculture. Consistent with common sense, ownership of mobile phones is most likely to influence the use of the device for collecting agricultural information considerably. In agreement with Tadesse and Bahiigwa (2015), education is critical to the use of the mobile phone because this requires some level of technical ability if full benefits of its use are to be leveraged. Family size positively influences the use of mobile phone, and this could be on account of the resulting lower shared family cost to own the device. Contrary to our expectation, the farming experience of household head, age and gender do not significantly determine the use of mobile phones to search for information. This suggests that the use of the device has a lot to do with the technical ability to use the mobile phone and also ownership.

Table 3. Factors influences mobile phone use

\begin{tabular}{ll}
\hline Mobile Phone Use & Coefficient (Std.Err.) \\
\hline Education & $0.465(0.096)^{* * *}$ \\
Mobile phone ownership & $3.119(0.594)^{* * *}$ \\
Gender & $-0.423(0.521)$ \\
Distance to cooperative & $-0.041(0.053)$ \\
Farming Experience & $-0.018(0.027)$ \\
Age & $-0.121(0.310)$ \\
Family size & $0.187(0.082)^{* *}$ \\
Maize sales (annual) & $0.000(0.000)$ \\
Constant & $-6.069(1.531)^{* * *}$ \\
\hline
\end{tabular}

Note. Figures in parentheses are standard errors of the coefficients, while $*, * *$, and $* * *$ indicate statistical significance levels at $10 \%, 5 \%$, and $1 \%$, respectively.

Source: Authors' estimation.

\subsection{What Would the Potential Output Be if Farmers Adopt the Use of Mobile Phones?}

The efficiency gap between the groups can be reduced to zero without altering the level of input, through non-users subscribing to the use of mobile phones. This would imply that all the farmers operate at the mean efficiency level of users (0.794; see Table 2). Using this efficiency figure, potential output is calculated by increasing non-users' output by 30 percent while maintaining inputs and the output of users. The reported increment in maize production is attributed solely to the boost in technical efficiency through the adoption of mobile phone use for accessing information (Table 4). This gives insight into one of the missing elements to increase output and become more productive. What could be the implication of this increment? 
Table 4. Potential output per capita

\begin{tabular}{llllll}
\hline Variable & & Actual & Potential & Difference & Difference per day \\
\hline \multirow{2}{*}{ Output } & Mean & 4537.74 & 5915.40 & 1377.66 & 3.774 \\
& per capita $(\mathrm{kgs})$ & 743.89 & 969.74 & 225.85 & 0.619 \\
\hline
\end{tabular}

Note. Six people (average family size) and 365 days are used to calculate daily per capita output.

Source: Authors' estimation.

To keep the conclusion about the causal effect of mobile phone use on potential output from being a moot point, an increment of output per capita per day of 619 grams (about $4 \mathrm{~kg}$ per household) indicates that maize production is not only efficient and sustainable but also reasonable when farmers make use of the device. Zambia is dependant on maize to the point that maize means food for most citizens if not all. Whether in the urban or rural areas, the majority of households depend on maize related food (nshima as popularly known) for all the day's meals, breakfast, lunch, and supper because it is relatively inexpensive. Zambia has had a mono-diet culture for decades heavily reliant on maize. According to Food and Agricultural Organization, a person consumes $133 \mathrm{~kg}$ of maize per year (364 grams per day) in Zambia (Chapoto, Govereh, Haggblade, \& Jayne, 2010; FAO, 2009). In view of this, the reported increment in Table 4 contributes a two days equivalent consumption level which could feed two more people per household for the rest of the year. Therefore more output implies hunger eradication, bearing in mind that such an output increment aligns well with food security essentials, i.e., quality, quantity, availability, and the SDG goal number 2 of zero hunger. This is very important because volatility in maize production drives food policy in the country.

\section{Conclusion and Policy Implication}

Despite the unmatched contribution of the agriculture sector to economic growth and rural development, farmers face severe challenges regarding access to information, leading to a lack of momentum for achieving higher levels of agricultural productivity. One of the significant accomplishments in Zambia is the expansion of mobile services in rural agricultural communities. The use of mobile phones in accessing agricultural information narrows the gap in the adoption of beneficial agricultural technology resulting in higher crop yields. At present, the level of mobile phone ownership in rural Zambia and mobile-enabled information services could reduce information asymmetry. However, there exists scant information on the impact of the mobile phone expansion, and yet it is a critical issue that policymakers need to comprehend. Therefore, this paper focuses on the impact of access to agricultural information using the mobile telephone on the productivity of maize producing farmers in Zambia.

PSM was employed to evaluate the impact of the adoption of mobile phone use in agriculture, and the result indicated that mobile phone use had facilitated significant improvement in productivity. Farmers have access to some agricultural information using the device such as weather forecasts, sources of input and prices, improved agricultural technologies, access to credit and other general agricultural information. The improvement in productivity translated to increased maize production which contributes to hunger eradication. Therefore we recommend policy support measures to facilitate the establishment of formal information centers as this will ensure that farmers are equipped with decision support and up-to-date information in the agricultural systems. Such actions will have substantial positive effects in improving smallholder and national food security which is fundamental in reducing poverty and hunger in rural Zambia. While access to information is the purpose of mobile phone use in agriculture, the outcome leading to hunger alleviation fuels the popularity of its use in rural settings.

Finally, the study is not without limitations as a cross-sectional data was used. Given that such studies are time specific, future studies making use of panel data to extend and corroborate our finding is strongly advocated.

\section{Acknowledgements}

We acknowledge the sponsorships of a project funded by the Priority Academic Program Development of Jiangsu Higher Education Institutions (PAPD) and the Higher Education Loans and Scholarships Board (HELSB) particularly the Board Chairperson-Mwenya Mapoma, the Director-Ireen Chirwa, and Professor Stephen Simukanga.

G.E.M. and X.T. designed the research and questionnaire. G.E.M., E.M., and M.C.M. conducted the household survey and collected all data. G.E.M., E.J.-P.A., M.K. and A.M.E. analyzed the data. G.E.M., E.M., and F.W. wrote the manuscript. X.T. reviewed and revised the paper. All the authors read and approved the final manuscript. 


\section{References}

Abadie, A., \& Imbens, G. W. (2006). Large sample properties of matching estimators for average treatment effects. Econometrica, 74(1), 235-267. https://doi.org/10.1111/j.1468-0262.2006.00655.x

Admassie, A., \& Ayele, G. (2004). Adoption of Improved Technology in Ethiopia. Ethiopian Development Research Institute.

Aina, L. (1985). Information needs and information-seeking involvement of farmers in six communities in Nigeria. Quarterly Bulletin (IAALD).

Aker, J. C. (2008). Does digital divide or provide? The impact of cell phones on grain markets in Niger.

Aker, J. C. (2010). Information from markets near and far: Mobile phones and agricultural markets in Niger. American Economic Journal: Applied Economics, 2(3), 46-59. https://doi.org/10.1257/app.2.3.46

Aker, J. C., \& Ksoll, C. (2016). Can mobile phones improve agricultural outcomes? Evidence from a randomized experiment in Niger. Food Policy, 60, 44-51. https://doi.org/10.1016/j.foodpol.2015.03.006

Aker, J. C., \& Mbiti, I. M. (2010). Mobile phones and economic development in Africa. Journal of Economic Perspectives, 24(3), 207-232. https://doi.org/10.1257/jep.24.3.207

Ali, J., \& Kumar, S. (2011). Information and communication technologies (ICTs) and farmers' decision-making across the agricultural supply chain. International Journal of Information Management, 31(2), 149-159. https://doi.org/10.1016/j.ijinfomgt.2010.07.008

Ango, A., Illo, A., Abdullahi, A., Maikasuwaand, M., \& Amina, A. (2013). Role of farm-radio agricultural programmes in disseminating agricultural technology to rural famers for agricultural development in Zaria, Kaduna State, Nigeria. Asian J. Agric. Ext. Econ. Sociol., 2(1), 54-68. https://doi.org/10.9734/AJAEES/ 2013/1988

Asongu, S. A., \& Kodila-Tedika, O. (2017). Is poverty in the African DNA (Gene)? South African Journal of Economics, 85(4), 533-552. https://doi.org/10.1111/saje.12165

Babu, S. C., Glendenning, C. J., Asenso-Okyere, K., \& Govindarajan, S. K. (2012). Farmers' information needs and search behaviors. International Food Policy Research Institute, Paper, 1165, 1-37.

Benin, S., Pratt, A. N., Wood, S., \& Guo, Z. (2011). Trends and spatial patterns in agricultural productivity in Africa, 1961-2010. ReSAKSS Annual Trends and Outlook Report, 2011(10.2499), 9780896298019.

Bravo-Ureta, B. E., Solís, D., López, V. H. M., Maripani, J. F., Thiam, A., \& Rivas, T. (2007). Technical efficiency in farming: A meta-regression analysis. Journal of Productivity Analysis, 27(1), $57-72$. https://doi.org/10.1007/s11123-006-0025-3

Brown, L. R. (2001). Eradicating hunger: A growing challenge.

Caliendo, M., \& Kopeinig, S. (2008). Some practical guidance for the implementation of propensity score matching. Journal of Economic Surveys, 22(1), 31-72. https://doi.org/10.1111/j.1467-6419.2007.00527.x

Chapoto, A., Govereh, J., Haggblade, S., \& Jayne, T. S. (2010). Staple food prices in Zambia. Paper presented at the Comesa Policy Seminar "Food Price Variability: Causes, Consequence, and Policy Options", Maputo, Comesa/MSU/IFPRI African Agricultural Markets Project.

Chukwuji, C. O., Inoni, O. E., \& Oyaide, W. J. (2006). A quantitative determination of allocative efficiency in broiler production in Delta State, Nigeria. Agriculturae Conspectus Scientificus, 71(1), 21-26.

CSO. (2017). Zambia Agriculture Status Report.

Dreze, J., Sen, A., \& Hussain, A. (1995). The political economy of hunger. Oxford University Press.

FAO, \& IFAD. (2012). The State of Food Insecurity in the World 2012-Economic growth is necessary but not sufficient to accelerate reduction of hunger and malnutrition. Rome, Italy: Food and Agriculture Organization of the United Nations.

FAO. (2009). FAO Food balance sheet. Retrieved from Rome. Italy. Retrieved from https://www.researchgate. net/deref/http $\% 3 \mathrm{~A} \% 2 \mathrm{~F} \% 2 \mathrm{Ffaostat}$.fao.org $\% 2 \mathrm{Fsite} \% 2 \mathrm{~F} 368 \% 2 \mathrm{Fdefault}$.aspx $\% 23$ ancor

Färe, R., Grosskopf, S., \& Lovell, C. K. (1984). The structure of technical efficiency. Topics in Production Theory (pp. 81-90). Springer. https://doi.org/10.1007/978-1-349-07123-4_6

Farrell, M. J. (1957). The measurement of productive efficiency. 
Ferguson, C. E. (1966). Production, Prices, and the Theory of Jointly-Derived Input Demand Functions. Economica, 33(132), 454-461. https://doi.org/10.2307/2552724

Hayami, Y., \& Ruttan, V. W. (1970). Agricultural productivity differences among countries. The American Economic Review, 60(5), 895-911.

Heinrich, C., Maffioli, A., \& Vazquez, G. (2010). A primer for applying propensity-score matching.

Jain, L., Kumar, H., \& Singla, R. (2015). Assessing mobile technology usage for knowledge dissemination among farmers in Punjab. Information Technology for Development, 21(4), 668-676. https://doi.org/ $10.1080 / 02681102.2013 .874325$

Kelemu, K. (2016). Impact of Mobile Telephone on Technical Efficiency of Wheat Growing Farmers in Ethiopia. International Journal of Research Studies in Agricultural Sciences, 2 (7), 1-9.

Kirk, M., Steele, J., Delbé, C., Crow, L., Keeble, J., Fricke, C., ... Bulloch, G. (2011). Connected Agriculture: The role of mobile in driving efficiency and sustainability in the food and agriculture value chain. Oxfam Policy and Practice: Agriculture, Food and Land, 11(6), 85-106.

Koopmans, T. C. (1951). An analysis of production as an efficient combination of activities. Activity Analysis of Production and Allocation.

Lynd, L. R., \& Woods, J. (2011). Perspective: A new hope for Africa. Nature, 474(7352), S20-S21. https://doi.org/10.1038/474S020a

Muzari, W., Gatsi, W., \& Muvhunzi, S. (2012). The impacts of technology adoption on smallholder agricultural productivity in sub-Saharan Africa: A review. Journal of Sustainable Development, 5(8), 69. https://doi.org/10.5539/jsd.v5n8p69

Rahman, S., \& Rahman, M. (2009). Impact of land fragmentation and resource ownership on productivity and efficiency: The case of rice producers in Bangladesh. Land Use Policy, 26(1), 95-103. https:/doi.org/ 10.1016/j.landusepol.2008.01.003

Rosenbaum, P. R., \& Rubin, D. B. (1983). The central role of the propensity score in observational studies for causal effects. Biometrika, 70(1), 41-55. https://doi.org/10.1093/biomet/70.1.41

Samuel, S. (2007). Intra-House Labour Allocation and Technical Efficiency Among Groundnuts Producers in Eastern Uganda (MSc. Thesis, Makerere University, Kampala, Uganda).

Sen, A. (1976). Famines as failures of exchange entitlements. Economic and Political Weekly, 1273-1280.

Sen, A. (1981). Ingredients of famine analysis: Availability and entitlements. The Quarterly Journal of Economics, 96(3), 433-464. https://doi.org/10.2307/1882681

Shimamoto, D., Yamada, H., \& Gummert, M. (2015). Mobile phones and market information: Evidence from rural Cambodia. Food Policy, 57, 135-141. https://doi.org/10.1016/j.foodpol.2015.10.005

Tadesse, G., \& Bahiigwa, G. (2015). Mobile phones and farmers' marketing decisions in Ethiopia. World Development, 68, 296-307. https://doi.org/10.1016/j.worlddev.2014.12.010

Thirtle, C., Lin, L., \& Piesse, J. (2003). The impact of research-led agricultural productivity growth on poverty reduction in Africa, Asia and Latin America. World Development, 31(12), 1959-1975. https://doi.org/ 10.1016/j.worlddev.2003.07.001

Verheye, W. H. (2000). Food production or food aid? An African challenge. Finance and Development, 37(4), 38.

Wheeler, T., \& Von Braun, J. (2013). Climate change impacts on global food security. Science, 341(6145), 508-513. https://doi.org/10.1126/science.1239402

Wiebe, K. D. (2003). Linking land quality, agricultural productivity, and food security. 


\section{Appendix A}

\section{Stochastic Frontier Analysis-Translog production function}

The empirical results estimated by maximum likelihood estimation are presented in Table A1. The overall fitness of the model is guaranteed by model specification tests and the log-likelihood tests. The value of lambda being significantly greater than zero is an expression of the significant effects of inefficiency in maize production, and is consistent with the hypotheses tests.

Table A1. SFA maximum likelihood estimates

\begin{tabular}{|c|c|c|c|}
\hline \multicolumn{2}{|c|}{ Stochastic Frontier Production Function } & \multicolumn{2}{|c|}{ Technical Inefficiency Function } \\
\hline lnproduct & Coefficient (Std.Err.) & Explanatory Variables & Coefficient (Std.Err.) \\
\hline lnFertilizer & $0.574(0.655)$ & Mobile phone use & $-0.236(0.052) * * *$ \\
\hline $\operatorname{lnLand}$ & $1.199(1.584)$ & Male family labor & $0.026(0.007) * * *$ \\
\hline lnLabor & $-0.865(0.780)$ & Female family labor & $0.011(0.018)$ \\
\hline $\ln$ Seed & $-0.870(0.983)$ & Sex of $\mathrm{HH}$ & $-0.040(0.046)$ \\
\hline InFertilizer_land & $0.226(0.190)$ & Farming experience & $-0.004(0.002) * *$ \\
\hline lnLabor_seed & $0.339(0.126) * * *$ & Education of $\mathrm{HH}$ & $-0.021(0.016)$ \\
\hline lnFertilizer_labor & $0.153(0.106)$ & Spouse education & $0.037(0.047)$ \\
\hline lnLand_labor & $-0.260(0.118) * *$ & Access to power & $-0.016(0.033)$ \\
\hline InFertilizer_seed & $-0.121(0.107)$ & Marital status & $-0.017(0.042)$ \\
\hline lnLand_seed & $0.033(0.149)$ & Cooperative membership & $-0.063(0.076)$ \\
\hline $0.5^{\mathrm{x}} \ln L a b o r \_2$ & $-0.076(0.043) *$ & Government subsidy & $-0.150(0.062) * *$ \\
\hline $0.5^{\mathrm{x}} \ln$ Land_2 & $-0.157(0.165)$ & Age of $\mathrm{HH}$ & $-0.040(0.027)$ \\
\hline $0.5^{\mathrm{x}} \operatorname{lnSeed} 2$ & $-0.092(0.074)$ & Distance farm to house & $-0.009(0.017)$ \\
\hline $0.5^{\mathrm{x}} \operatorname{lnFertilizer} 2$ & $-0.104(0.055) *$ & Constant & $-0.536(0.204) * * *$ \\
\hline Scale elasticity & 0.038 & Lambda & $0.639(0.070) * * *$ \\
\hline Log-likelihood & 59.761 & Mean & 0.664 \\
\hline Wald chi2 & $1506.180 * * *$ & & \\
\hline Observations & 195 & & \\
\hline
\end{tabular}

Note. Chi-square values of 1506.18 and 80.24 were statistically significant at the $1 \%$ confidence level, facilitating the rejection of the null hypotheses that the Cobb-Douglas production function can represent the data well and inefficiency effects are absent from the model. Figures in parentheses are standard errors of the coefficients, while $*, * *$ and $* * *$ indicates statistical significance levels at $10 \%, 5 \%$, and $1 \%$, respectively. Source: Authors' estimation.

\section{Copyrights}

Copyright for this article is retained by the author(s), with first publication rights granted to the journal.

This is an open-access article distributed under the terms and conditions of the Creative Commons Attribution license (http://creativecommons.org/licenses/by/4.0/). 